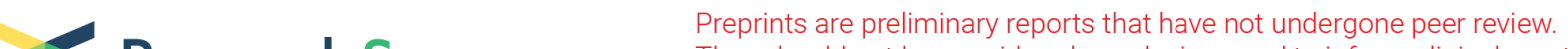 Research Square
or referenced by the media as validated information.
}

\section{Risk factors for renal alterations in patients with hematological cancer undergoing antineoplastic treatment}

\section{Priscila Nunes Costa Travassos}

Federal University of Ceara Faculty of Medicine: Faculdade de Medicina da Universidade Federal do Ceara

\section{Paulo Goberlânio Barros Silva ( $\sim$ paulo_goberlanio@yahoo.com.br )} Instituto do Câncer do Ceará: Instituto do Cancer do Ceara https://orcid.org/0000-0002-1513-9027

\section{Milena Oliveira Freitas}

Universidade Federal do Ceara

\section{Marcus Davis Machado Braga}

Faculdade de Medicina da Universidade Federal do Ceara

\section{Fernando Barroso Duarte}

Universidade Federal do Ceara Hospital Universitario Walter Cantidio

Jéssica Karen de Oliveira Maia

Universidade Federal do Ceara Hospital Universitario Walter Cantidio

\section{Helena Pitombeira}

Universidade Federal do Ceara Hospital Universitario Walter Cantidio Jacqueline Holanda de Sousa

Universidade Federal do Ceara Hospital Universitario Walter Cantidio Ana Paula Negreiros Nunes Alves

Universidade Federal do Ceara Faculdade de Farmacia Odontologia e Enfermagem

\section{Research Article}

Keywords: Lymphoma, Multiple myeloma, Leukemia, Chemotherapy, Glomerular Filtration Rate.

Posted Date: May 3rd, 2021

DOI: https://doi.org/10.21203/rs.3.rs-371536/v1

License: (c) (1) This work is licensed under a Creative Commons Attribution 4.0 International License. Read Full License 


\section{Abstract}

Purpose Antineoplastic treatments, mainly chemotherapy, affect the kidneys, causing toxicity, and can trigger acute and long-term chronic kidney injury. The objective of this study was to analyze the prevalence of renal disorders in patients with oncohematological neoplasms under antineoplastic treatment.

Methods This is a retrospective cohort study involving 75 patients affected by hematological cancer who underwent chemotherapy between 2012 and 2108 in the Hematology Sector of the Walter Cantídeo University Hospital of the Federal University of Ceará. Sociodemographic and clinical data, blood biochemical assessment, and Glomerular Filtration Rate (GFR) were analyzed using the Chronic Kidney Disease Epidemiology Collaboration (CKD-EPI) equation. The data were tabulated, transferred to the Statistical Package for the Social Sciences software, version 20.0, and analyzed using Fisher's exact test or Pearson's chi-square test, followed by the Mann-Whitney test. Additionally, the variables were treated using a multinomial logistic regression model $(p<0.05)$.

Results The prevalence of renal disorders was $52.4 \%$, considering the episodes of GFR through the CKDEPI equation. There was an association between the reduction in GFR and the variables: female gender ( $p$ $=0.002)$, diagnosis of multiple myeloma $(p=0.008)$, start of treatment within 40 days $(p=0.005)$, protocol Cyclophosphamide, Oncovin, Prednisone $(p=0.026)$, Idarubicin $(p=0.032)$, Vidaza protocol, Dexamethasone, Cyclophosphamide $(p<0.001)$, Zoledronate $(p<0.001)$ and Pamidronate $(p=0.012)$. It was also observed that the Cancer and Leukemia Group B protocol $(p<0.001)$ is inversely associated with a reduction in GFR.

Conclusions The prevalence of renal disorders is high in the service evaluated, requiring periodic monitoring of the evaluation of renal function, since the reduction in GFR is statistically associated with different protocols used.

\section{Introduction}

Hematological cancers, among the most common, are classified into leukemias, lymphomas, and multiple myeloma. These neoplasms affect about 22,780 thousand people a year, being more incidents in men than in women. Among them, the most frequent is non-Hodgkin lymphoma, with 10,240 thousand cases, soon followed by leukemias with 10,070 thousand cases in Brazil [1].

The options for the antineoplastic treatment plan consist of Chemotherapy (CT), radiation therapy, gene therapy, pharmacological therapy, and surgical resection. However, it usually consists of a combination of these modalities [2]. The toxicity of therapeutic modalities, mainly CT, affects the kidneys, which are the preferred elimination pathway for chemotherapeutic drugs. Nephrotoxic drugs cause kidney damage due to the delay or interruption of treatment, or due to excess chemotherapy and its difficulty in removing it from the body [3]. 
In association with cancer, renal involvement is evident with an incidence of $18 \%$ only in the first year of diagnosis, revealing to affect this sick population more when compared to the general population, which is approximately 1,000 per year. Five years after diagnosis, this rate increases to $43 \%$ in patients with solid tumors and bone metastases [3, 4].

In lymphomas, renal impairment reaches about $33 \%$ in myeloid leukemia, in myelodysplastic syndrome, this number is $36 \%$, and in multiple myeloma, it happens in about 30 to $40 \%$ of the patients, and, during the progression of the disease, this index increases to $50 \%$ [5-9].

Once installed, renal dysfunction causes the breakdown of homeostasis leading to the appearance of edema, systemic arterial hypertension, accumulation of sodium chloride, hyperkalemia, hyponatremia, hypophosphatemia, anemia, change in coagulation, suppression of the immune system, metabolic acidosis and, in its consequence, pulmonary hyperventilation as a compensatory mechanism, azotemia, and uremic encephalopathy [10].

Despite therapeutic advances, patients with hematological cancers are more vulnerable to kidney changes, Acute Kidney Injury (AKI), and Chronic Kidney Disease (CKD), when opposed to patients with other types of malignancies, in addition to having worse prognosis [11, 12].

Therefore, we sought to analyze the prevalence of renal disorders in patients with hematological neoplasms under antineoplastic chemotherapy treatment in the Hematology Sector of the Walter Cantídeo University Hospital of the Federal University of Ceará, from 2012 to 2018.

\section{Methods}

This is a retrospective cohort study, with a descriptive and analytical approach developed in a reference hospital (HUWC-UFC), in the Hematology Sector, located in the city of Fortaleza-CE.

The sample consisted of 75 patients, over 18 years old, with hematological neoplasia, who underwent or were still undergoing chemotherapy in the period from 2012 to 2018 at the hematology service.

Data were collected by consulting printed medical records, digital records, and other documents of the institution. The following variables were tabulated: $A$ ) sociodemographic data: name, age (considering up to 50 and over 50 years), sex (male and female), education (illiterate, elementary, middle, upper), race (white, brown or black), marital status (with a partner or without a partner), place of birth; B) clinical aspects: presence of comorbidities, weight, height, Body Mass Index (BMI), BMI classification, dental care, type of neoplasia, remission, time of treatment initiation after diagnosis, type of antineoplastic treatment, type of conditioning, previous transplantation and what type of transplantation, medications in use, place of chemotherapy application, protocol, number of cycles, medications in use, kidney injury relapse, duration of antineoplastic treatment; C) Glomerular Filtration Rate: using the Chronic Kidney Disease Epidemiology Collaboration (CKD-EPI) equation. 
For the basal creatinine value, the first measurement found in the medical records of each patient was adopted, following the recommendations of KDIGO, and to estimate GFR, the formula CKD-EPI was used because of its accuracy is more effective than when compared with the others [13], and thus the outcome variable was determined.

Categorical data were expressed as absolute frequency, considering the patient as the sample unit. The clinical evaluation event was adopted as the sample unit for the assessment of CKD risk factors, which were crossed using Fisher's exact test or Pearson's chi-square test. Examination data were expressed as means and standard deviations and analyzed using the Mann-Whitney test (non-parametric data).

After identifying the clinical variables significantly associated with increased risk of CKD-EPI, these were divided into two levels: clinical-epidemiological variables and therapeutic variables. At each level, these variables were analyzed using a multinomial logistic regression model, and after that, the variables independently associated with CKD-EPI were selected at each level for multilevel analysis using the same model. For all analyzes, $p<0.05$ was considered statistically significant.

The research is in accordance with ethical principles, and the Ethics Committee for Research on Human Beings of the Faculty of Medicine (UFC) was firstly approved with CAAE 87952818.7.0000.5054 and then by the Ethics Committee of the Walter Cantídeo University Hospital (UFC) ) under CAAE number 87952818.7.3001.5045.

\section{Results}

\section{Sociodemographic profile of the sample and influence on the incidence of CDK-EPI episodes}

Sociodemographic characteristics revealed that of the 75 patients included in the study, the majority $(n=$ 47) were in the age group above 50 years old, representing $62.7 \%, 39$ were female (52.0\%), 44 brown (95.7\%), 29 had a partner (53.7\%), and 46 lived in Fortaleza or the metropolitan area (61.3\%). Regarding the level of education, it is emphasized that $10(31.3 \%)$ patients had incomplete higher education, seven incomplete high school (21.9\%), and six complete elementary school (18.8\%) (Table 1). 
Table 1

Sociodemographic profile and its influence on the reduction of CKD-EPI in patients undergoing chemotherapy under analysis of renal function at the Hospital Universitário Walter Cantídio from 2012 to 2018.

CDK-EPI $(n=450)^{b}$

Sample Normal $\quad$ Reduced $\quad$ p-value

Age

Up to 50

$28 \quad 37.3 \% \quad 153^{*} \quad 71.5 \% \quad 30 \quad 12.7 \% \quad<0.001$

$>50$

$47 \quad 62.7 \% \quad 6$

61

$28.5 \%$

206*

$87.3 \%$

Sex

Female

$39 \quad 52.0 \% \quad 105$

$49.1 \%$

$147 *$

$62.3 \%$

0.005

Male

36

$48.0 \% \quad 109 * \quad 50.9 \%$

89

$37.7 \%$

Race

White

$1 \quad 2.2 \% \quad 0$

$0.0 \%$

$15^{*}$

$7.9 \%$

$<0.001$

Brown

44

Black

$1 \quad 2.2 \% \quad 0$

$100.0 \%$

$17290.5 \%$

Marital status

With partner

$29 \quad 53.7 \% \quad 77$

$49.4 \%$

79

$46.7 \%$

0.638

Without partner

$25 \quad 46.3 \% \quad 79$

$50.6 \%$

90

$53.3 \%$

\section{Education}

Illiterate

$1 \quad 3.1 \% \quad 0$

$0.0 \%$

10 *

$9.5 \%<0.001$

Incomplete elementary school

2

$6.3 \% \quad 1$

$0.9 \%$

3*

$2.9 \%$

Complete elementary school

$6 \quad 18.8 \% \quad 21$

$19.3 \%$

$35 *$

$33.3 \%$

Incomplete high school

Complete high school

\begin{tabular}{lll}
7 & $21.9 \%$ & 10 \\
\hline & $3.1 \%$ & $11 *$
\end{tabular}

$9.2 \%$

$17 *$

$16.2 \%$

Incomplete higher

1

Graduated

10

\section{Place of Birth}

Fortaleza/Metropolitan area

$46 \quad 61.3 \% \quad 113$

$52.8 \%$

$153 *$

$64.8 \%$

0.010

Data expressed as absolute frequency and percentage. ${ }^{*} p<0.05$, Fisher's exact test or Pearson's chi-

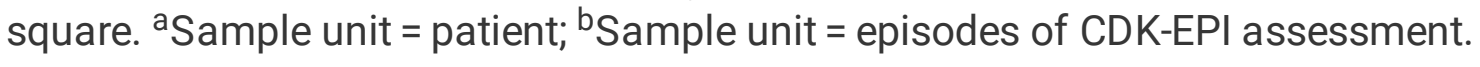




\begin{tabular}{|c|c|c|c|c|c|c|}
\hline \multirow[b]{2}{*}{ Countryside } & \multicolumn{5}{|c|}{ CDK-EPI $(n=450)^{b}$} & \\
\hline & 29 & $38.7 \%$ & $101 *$ & $47.2 \%$ & 83 & $35.2 \%$ \\
\hline
\end{tabular}

Patients over the age of 50 had a more significant number of episodes with reduced CKD-EPI $(p<0.001)$ as well as female $(p=0.005)$, being from Fortaleza or metropolitan region $(p=0.010)$ and being patients of white color $(p<0.001)$. Education is inversely associated with these episodes $(p<0.001)$ (Table 1$)$.

\section{Sample comorbidity profile and influence on the incidence of CDK-EPI episodes}

There was a prevalence of Systemic Arterial Hypertension (SAH) as comorbidity, affecting 29 patients (38.7\%), the classification of pre-obesity according to the Body Mass Index (BMI) was present in 30 patients $(40.0 \%)$ and obesity I in 27 patients (36\%). Non-dental follow-up was present in 62 patients (82.7\%), the diagnosis of Multiple Myeloma (MM) affected about $33(44.0 \%)$ and, concerning remission, chemotherapy as a type of treatment and not transplantation accounted for $63(84.0 \%), 72(96.0 \%)$ and $66(88.0 \%)$ respectively (Table 2 ). 
Table 2

Clinical and admission profile and its influences on the reduction of CKD-EPI in patients undergoing chemotherapy under analysis of renal function at the Hospital Universitário Walter Cantídio from 2012 to 2018.

$$
\text { CKD-EPI }(n=450)^{b}
$$

$\begin{array}{lll}\text { Sample } \quad \text { Normal } & \text { Reduced } & \begin{array}{l}\mathrm{p}- \\ \text { value }\end{array}\end{array}$

\section{Comorbidities}

Systemic Arterial Hypertension

$29 \quad 38.7 \% \quad 33 \quad 15.4 \% \quad 143 * \quad 60.6 \%$

Diabetes Mellitus

$12 \quad 16.0 \% \quad 10$

$4.7 \%$

$62 *$

$26.3 \%<$

0.001

Coronary disease

$1 \quad 1.3 \% \quad 0$

$0.0 \% \quad 10$ *

$4.2 \%$

0.002

Chronic Obstructive Pulmonary

Disease

$\begin{array}{lllllll}1 & 1.3 \% & 0 & 0.0 \% & 4 & 1.7 \% & 0.056\end{array}$

Others

$12 \quad 16 \% \quad 11$

$5.1 \%$

75*

$31.8 \%$

$<$

0.001

\section{Body mass index}

Normal

\section{Pre-obese}

Obesity I

Obesity II

Obesity III

\section{Dental care}

No

Yes

\section{Diagnosis}

Multiple myeloma

Lymphoid leukemia

Myeloid leukemia

$5 \quad 6.7 \% \quad 27^{\star}$

$30 \quad 40.0 \% \quad 90^{*}$

$27 \quad 36.0 \% \quad 51$

$10 \quad 13.3 \%$

$\begin{array}{lll}3 & 4.0 \% & 19\end{array}$

27
19

62

$82.7 \%$

172

$13 \quad 17.3 \%$

42

$33 \quad 44.0 \% \quad 33$

$\begin{array}{lll}10 & 13.3 \% & 58^{*} \\ 17 & 22.7 \% & 91^{*}\end{array}$

17

$12.6 \%$

10

$4.2 \%$

$<$

0.001

0.001

$42.1 \% \quad 59 \quad 25.0 \%$

$23.8 \% \quad 127 * \quad 53.8 \%$

\begin{tabular}{lll}
$12.6 \%$ & 27 & $11.4 \%$ \\
\hline $8.9 \%$ & 13 & $5.5 \%$ \\
\hline
\end{tabular}

0.001 


\section{CKD-EPI $(n=450)^{b}$}

Lymphoma

Remission

No

Yes

Treatment type

CT

$\mathrm{CT}+\mathrm{RDT}$

Transplant

No

Yes

Medications in use

Acyclovir

Bactrim

Fluconazole

Levofloxacin

Others

Initial renal function

Normal

Acute renal failure

Chronic kidney disease

Hemodialysis

No

Yes

Data expressed as absolute frequency and percentage. ${ }^{*} p<0.05$, Fisher's exact test or Pearson's chi-

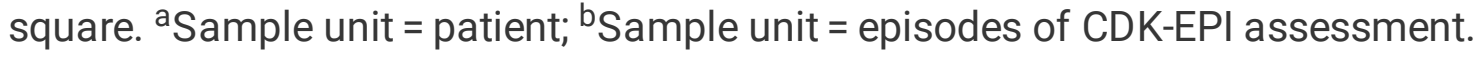

$63 \quad 84.0 \% \quad 203^{*} \quad 94.9 \% \quad 193 \quad 81.8 \%<$

$12 \quad 16.0 \% \quad 11 \quad 5.1 \% \quad 43^{*} \quad 18.2 \%$

$7296.0 \% 200 \quad 93.5 \% \quad 236 * 100.0 \%<$

0.001

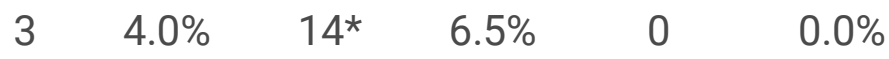

$66 \quad 88.0 \% \quad 205^{*} \quad 95.8 \% \quad 199 \quad 84.3 \% \quad<$

0.001

$9 \quad 12.0 \% \quad 9 \quad 4.2 \% \quad 37 * \quad 15.7 \%$

$\begin{array}{lllllll}33 & 44.0 \% & 120 * & 56.1 \% & 105 & 44.5 \% & 0.014\end{array}$

$41 \quad 54.7 \% \quad 117 \quad 54.7 \% \quad 177 * \quad 75.0 \%<$

0.001

$\begin{array}{llllll}4 & 5.3 \% & 30 * & 14.0 \% & 12 & 5.1 \%\end{array}$

$\begin{array}{lllllll}3 & 4.0 \% & 25^{*} & 11.7 \% & 12 & 5.1 \% & 0.011\end{array}$

$32 \quad 42.7 \% 54 \quad 25.2 \% \quad 143^{*} \quad 60.6 \%<$

0.001 


\section{CKD-EPI $(n=450)^{b}$}

\section{Place of application}

\begin{tabular}{lllllllll} 
Outpatient & 67 & $89.3 \%$ & 130 & $60.7 \%$ & $212^{*}$ & $89.8 \%$ & $<$ \\
\hline Inpatient & 8 & $10.7 \%$ & $84^{*}$ & $39.3 \%$ & 24 & $10.2 \%$ & \\
\hline
\end{tabular}

\section{Time to start treatment}

$\begin{array}{lllllllll}\text { Up to } 40 \text { days } & 37 & 49.3 \% & 134 * & 62.6 \% & 126 & 53.4 \% & 0.048 \\ >40 \text { days } & 38 & 50.7 \% & 80 & 37.4 \% & 110 * & 46.6 \% & \end{array}$

Data expressed as absolute frequency and percentage. ${ }^{*} p<0.05$, Fisher's exact test or Pearson's chi-

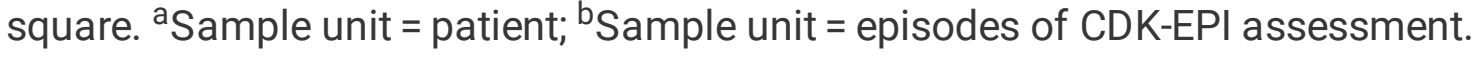

According to the additional medications, Bactrim stood out among the others. Forty-one patients used it $(54.7 \%)$. Thirty-three patients used acyclovir (44.0\%). Thirty-two patients $(42.7 \%)$ used other drugs (amitril, atenolol, omeprazole, metformin, simvastatin, atorvastatin, enalapril, aspirin, carvedilol, itraconazole, captopril, thalidomide, glibenclamide, propranolol, amlodipine, allopurinol, hydrochlorothiazide, gliclazide, Puran, nifedipine, furosemide, folic acid, Tazocin, dexamethasone, insulin, pregabalin, prednisone) (Table 2).

Almost the entire population had a normal initial renal function, 70 patients (93.3\%), and 74 did not use hemodialysis (98.7). Regarding the place where the treatment was applied, the vast majority of patients were administered at the outpatient clinic, 67 (89.3\%) and concerning the start of medications, part of the patients started after 40 days after diagnosis, representing $38(50,7 \%)$ (Table 2$)$.

Regarding the clinical and admission profile of the patients, it was observed that $S A H(p<0.001), D M(p<$ $0.001)$, coronary disease $(p=0.002)$, other comorbidities $(p<0.001)$ of the most varied, grade I obesity $(p$ $<0.001)$ are directly associated with a reduction in CKD-EPI. Although the lack of dental follow-up did not show statistical significance $(p=0.056)$, there is a trend when associated with a decrease in GFR (Table 2).

Patients diagnosed with multiple myeloma $(p<0.001)$ revealed more GFR reduction events as well as those who presented remission $(p<0.001)$, exclusive treatment with chemotherapy $(p<0.001)$ and transplantation $(p<0.001)$ (Table 2$)$.

Acyclovir $(p=0.014)$, fluconazole $(p=0.001)$ and levofloxacin $(p=0.011)$ were inversely associated with a decrease in CKD-EPI whereas, the use of bactrim $(p<0.001)$ and other drugs $(p<0.001)$ showed a direct relationship with this change. According to renal function, patients who started treatment with AKI or CKD $(p=0.003)$ also had more episodes of reduced GFR as well as hemodialysis $(p=0.032)$ and progression to $\operatorname{CKD}(p<0.001)$ (Table 2). 
Patients who underwent treatment at the outpatient clinic $(p<0.001)$ were directly associated with renal dysfunction. It should be noted, however, that the sample studied consisted almost entirely of outpatients. There was also a higher number of dysfunctional episodes $(p=0.048)$ in patients who started treatment within 40 days after diagnosis (Table 2).

\section{Therapeutic profile of the sample and influence of the scheme on the incidence of CDK-EPI episodes}

The 75 patients participating in the research totaled 985 episodes of analysis (data collection), with a mean of $6.6 \pm 6.8$ and a median of 4 events per patient with a minimum and maximum of 1 to 46 events, respectively. Most patients underwent 1 to 2 cycles of CT, totaling 302 (30.7\%) (Table 3).

Table 3

Clinical and admission profile of patients undergoing chemotherapy under analysis of renal function at Hospital Universitário Walter Cantídio from 2012 to 2018. Fortaleza / CE, Brazil. 2018.

\begin{tabular}{|lll|}
\hline & $\mathbf{n}$ & $\%$ \\
\hline Total number of episodes evaluated & 985 & 100 \\
\hline Evaluation cycle & 302 & 30.7 \\
\hline 1st or 2nd cycle & 224 & 22.7 \\
\hline 3rd or 4th cycle & 297 & 30.2 \\
\hline 5th to 10th cycle & 162 & 16.4 \\
\hline 11th or higher & & \\
\hline CKD-EPI ( $\mathbf{n}=\mathbf{4 5 0})$ & 214 & 47.6 \\
\hline Normal & 236 & 52.4 \\
\hline Reduced & & \\
\hline GFR classification $(\mathbf{n}=\mathbf{4 5 0})$ & 212 & 47.1 \\
\hline Normal & 123 & 27.3 \\
\hline Mild decrease & 49 & 10.9 \\
\hline Mild to moderate & 39 & 8.7 \\
\hline Moderate to severe & 21 & 4.7 \\
\hline Severe decrease & 6 & 1.3 \\
\hline Kidney failure & & \\
\hline $\begin{array}{l}\text { Data expressed as absolute frequency and percentage. * } \mathrm{p}<0.05 \text {, Fisher's exact test or Pearson's chi- } \\
\text { square. TGF = Glomerular filtration rate }\end{array}$ & & \\
\hline
\end{tabular}


When the estimate of GFR was assessed using the CKD-EPI formula, a result of 450 analyzes was obtained, since not all patients had a creatinine value. Of these, $236(52.4 \%)$ had reduced GFR and categorizing the GFR determined by the result of the CKD-EPI formula; it was found that $212(47.1 \%)$ episodes were considered normal. This variable was used for association with the other sociodemographic, clinical, and therapeutic variables (Table 3 ).

Analyzing the therapeutic profile, it was possible to dichotomize groups: inversely associated with a reduction in GFR (Cyclophosphamide, Oncovin, Prednisone (COP) $p=0.004$, Transretinoic Acid (ATRA) $p<$ 0.001 , Idarubicin $p<0.001$, Daunorubicin $p<0.001$, Filgrastim $p=0.003$, Cancer and Leukemia Group $B$ (CALGB) $p<0.001$, Cytarabine $p=0.004$, Procarbazine, Oncovin, Mecloretamine, Prednisone (POMP) $p=$ 0.003 , Imatinib $p=0.027$, other drugs $p=0.003$ ) and those directly related the decrease in GFR (Vidaza, Dexamethasone, Cyclophosphamide (VDC) $p<0.001$, Zoledronate $p<0.001$, Pamidronate $p<0.001$, Talcidex $\mathrm{p}<0.001)$ (Table 4). 
Table 4

Influence of the therapeutic profile on the reduction of CKD-EPI in patients undergoing chemotherapy under analysis of renal function at Hospital Universitário Walter Cantídio from 2012 to 2018.

\section{CKD-EPI $(n=450)$}

Normal

\section{Cycle}

\begin{tabular}{lllll}
\hline 1st or 2 nd cycle & 67 & $31.3 \%$ & 91 & $38.6 \%$ \\
\hline 3rd or 4th cycle & 41 & $19.2 \%$ & 52 & $22.0 \%$ \\
\hline 5th to 10th cycle & 66 & $30.8 \%$ & 64 & $27.1 \%$ \\
\hline 11th or higher & 40 & $18.7 \%$ & 29 & $12.3 \%$
\end{tabular}

\section{Therapeutic schemes}

\begin{tabular}{llllll} 
Anti CD20 & 7 & $3.3 \%$ & 2 & $0.8 \%$ & 0.067 \\
COP & $10^{*}$ & $4.7 \%$ & 1 & $0.4 \%$ & 0.004 \\
CHOP & 1 & $0.5 \%$ & 4 & $1.7 \%$ & 0.215 \\
\hline Anti CD21 & 0 & $0.0 \%$ & 1 & $0.4 \%$ & 0.340 \\
\hline Anti CD22 & 0 & $0.0 \%$ & 0 & $0.0 \%$ & 1.000 \\
\hline ATRA & $48^{*}$ & $22.4 \%$ & 9 & $3.8 \%$ & $<0.001$ \\
Idarubicin & $25^{*}$ & $11.7 \%$ & 2 & $0.8 \%$ & $<0.001$ \\
\hline Daunorubicin & $10^{*}$ & $4.7 \%$ & 0 & $0.0 \%$ & 0.001 \\
\hline Mitoxantrone & 0 & $0.0 \%$ & 0 & $0.0 \%$ & 1.000 \\
\hline Filgrastim & $8^{*}$ & $3.7 \%$ & 0 & $0.0 \%$ & 0.003 \\
\hline CalgB & $51^{*}$ & $23.8 \%$ & 5 & $2.1 \%$ & $<0.001$ \\
\hline Mabthera & 1 & $0.5 \%$ & 0 & $0.0 \%$ & 0.293 \\
\hline Cytarabine & $12^{*}$ & $5.6 \%$ & 2 & $0.8 \%$ & 0.004 \\
\hline Daunoblastin & 1 & $0.5 \%$ & 1 & $0.4 \%$ & 0.945 \\
\hline VDC & 5 & $2.3 \%$ & $76 *$ & $32.2 \%$ & $<0.001$
\end{tabular}

Data expressed as absolute frequency and percentage. * $p<0.05$, Fisher's exact test or Pearson's chisquare. Sample unit = event. CHOP: Cyclophosphamide, Hydroxidoxorubicin, Oncovin, Prednisone. CalgB: Cancer and Leukemia Group B. POMP: Procarbazine, Oncovin, Mecloretamina, Prednisone. VDC: Velcade, Cyclophosphamide, and Dexamethasone. ATRA: Trans-retinoic acid. FLAG: Fludarabine, ARA-C, and Idarubicin. **Rituximab, GVD, ICE, ABVD, Hydroxyurea, Vesanoid, 6mercaptopurine, methotrexate, MADIT, PVAB, GVM, FC Lite, FCR, Hipercvad cycle A. 


\begin{tabular}{|c|c|c|c|c|c|}
\hline \multirow[b]{2}{*}{ Zoledronate } & \multicolumn{5}{|c|}{ CKD-EPI $(n=450)$} \\
\hline & 12 & $5.6 \%$ & $74^{\star}$ & $31.4 \%$ & $<0.001$ \\
\hline Pamidronate & 4 & $1.9 \%$ & $25^{\star}$ & $10.6 \%$ & $<0.001$ \\
\hline POMP & $8^{*}$ & $3.7 \%$ & 0 & $0.0 \%$ & 0.003 \\
\hline Talcidex & 9 & $4.2 \%$ & $34^{\star}$ & $14.4 \%$ & $<0.001$ \\
\hline Nivolumab & 0 & $0.0 \%$ & 0 & $0.0 \%$ & 1.000 \\
\hline Imatinib & $11^{*}$ & $5.1 \%$ & 3 & $1.3 \%$ & 0.027 \\
\hline FLAG & 13 & $6.1 \%$ & 12 & $5.1 \%$ & 0.647 \\
\hline Vidaza & 0 & $0.0 \%$ & 0 & $0.0 \%$ & 1.000 \\
\hline Brentuximab & 3 & $1.4 \%$ & 0 & $0.0 \%$ & 0.068 \\
\hline Other drugs ** & $22^{\star}$ & $10.3 \%$ & 8 & $3.4 \%$ & 0.003 \\
\hline \multicolumn{6}{|c|}{$\begin{array}{l}\text { Data expressed as absolute frequency and percentage. }{ }^{\star} p<0.05 \text {, Fisher's exact test or Pearson's chi } \\
\text { square. Sample unit = event. CHOP: Cyclophosphamide, Hydroxidoxorubicin, Oncovin, Prednisone. } \\
\text { CalgB: Cancer and Leukemia Group B. POMP: Procarbazine, Oncovin, Mecloretamina, Prednisone. } \\
\text { VDC: Velcade, Cyclophosphamide, and Dexamethasone. ATRA: Trans-retinoic acid. FLAG: } \\
\text { Fludarabine, ARA-C, and Idarubicin. **Rituximab, GVD, ICE, ABVD, Hydroxyurea, Vesanoid, } \\
\text { 6mercaptopurine, methotrexate, MADIT, PVAB, GVM, FC Lite, FCR, Hipercvad cycle A. }\end{array}$} \\
\hline
\end{tabular}

When the multivariate analysis of the variables that showed significant relevance of the sociodemographic and clinical admission aspects was performed, it was found that being female increased the chance of episodes with a reduction in the CKD-EPI index by 18.75 times. Also, the diagnosis of MM increased this prevalence by 4,111.01 times, as well as the initiation of treatment within 40 days after the diagnosis increased the risk by 103.25 times (Table 5 ). 


\begin{tabular}{|c|c|c|c|c|}
\hline \multirow[b]{2}{*}{$\begin{array}{l}\text { Time to start treatment (Up to } 40 \\
\text { days) }\end{array}$} & \multicolumn{2}{|c|}{ Multivariate } & \multicolumn{2}{|c|}{ Multilevel } \\
\hline & 0.005 & $\begin{array}{l}103.25(4.16- \\
2.559 .69)\end{array}$ & 0.059 & - \\
\hline COP & 0.026 & $0.09(0.01-0.75)$ & 0.116 & - \\
\hline ATRA & 0.122 & - & - & - \\
\hline Idarubicin & 0.032 & $0.12(0.02-0.84)$ & 0.134 & - \\
\hline Daunorubicin & 0.988 & - & - & - \\
\hline Filgastrin & 0.989 & - & - & - \\
\hline CalgB & $<.001$ & $0.09(0.03-0.26)$ & 0.005 & $\begin{array}{l}0.23(0.08- \\
0.64)\end{array}$ \\
\hline Cytarabine & 0.765 & - & - & - \\
\hline VDC & $<001$ & $11.7(4.09-33.85)$ & $<.001$ & $\begin{array}{l}10.64(3.78- \\
29.86)\end{array}$ \\
\hline Zoledronate & $<.001$ & $4.42(1.97-9.92)$ & 0.006 & $\begin{array}{l}3.20(1.41- \\
7.29)\end{array}$ \\
\hline Pamidronate & 0.012 & $4.60(1.40-15.12)$ & 0.032 & $\begin{array}{l}3.86(1.12- \\
13.32)\end{array}$ \\
\hline POMP & 0.989 & - & - & - \\
\hline Talcidity & 0.052 & - & - & - \\
\hline Imatinib & 0.136 & - & - & - \\
\hline Granulokine & 1.000 & - & - & - \\
\hline Others & 0.025 & $0.32(0.12-0.87)$ & 0.21 & - \\
\hline
\end{tabular}

When performing the same procedure with the variables involved in the treatment, it was found that the use of COP, Idarubicin, CalgB, and others were inversely associated, reducing by $0.09,0.12,0.09$ and 0.32 times, in this order, the prevalence of episodes with decreased CKD-EPI, independently of the others. However, the use of VDC, Zoledronate, Pamidronate increased, respectively, 11.77, 4.42, 4.60 the chances of occurring the renal dysfunction event (Table 5).

Finally, another analysis of the variables described above was made, highlighting that, independently, the female gender and the diagnosis of MM are associated with a greater probability of occurring episodes 
with renal dysfunction in 2.26 and 5.75 times, respectively. This fact also happened with the use of Vidaza, Zoledronate, and Pamidronate, increasing the chances by 10.64, 3.20, and 3.86 times, respectively. On the other hand, the use of CalgB was inversely associated with the occurrence of episodes with low GFR, reduced by 0.23 times (Table 5 ).

\section{Discussion}

Renal impairment in patients with oncological hematology mainly comes from nephrotoxicity caused by the excretion of chemotherapy drugs. The dysfunctionality of this organ relates to the suspension of antineoplastic treatment, increased costs, reduced quality of life, and, among others, the increase in mortality $[14,11,15,16]$.

The present research, evaluated in episodes, found that $52.4 \%$ of the participants had reduced GFR according to the result of the CKD-EPI formula. One study showed that, in patients with CLL, approximately $15 \%$ of the patients developed some degree of renal dysfunction [17].

The significance of females with a higher number of episodes of reduced GFR may be associated with MM, and this fact is reaffirmed by other studies in which women are predominant with this disease [18$20]$ and patients with $\mathrm{MM}$ are more prone to kidney injury [21,22]. Research shows that, in developing countries, this scenario is visualized, but when it comes to first world countries, there is a balance between the sexes in the diagnosis of MM [23].

The influence of the diagnosis of MM with renal impairment has a broad scientific basis since 20 to $40 \%$ of patients with MM have renal dysfunction at the time of diagnosis. There are reports that the chemotherapy plan can reverse this dysfunctionality even in patients with low GFR rates [24]. However, the interaction of MM with renal dysfunction impacts on the survival time of affected patients, presenting an average of two years when renal function is normal and, in the presence of failure, the time is reduced by $50 \%[25-27]$.

The CalgB protocol is applied in hematological neoplasms, mainly in leukemias and their various aspects. The scheme in question in the present study is composed of oncovin, dexamethasone, and doxorubicin showing relation with GFR. Oncovin is a chemotherapy that has the main adverse effect on neurotoxicity $[28,29]$. Dexamethasone is a potent anti-inflammatory used in the treatment of numerous diseases whose mechanism of action is aimed at minimizing the inflammatory state (attenuating chemokines and cytokines) and increasing vascular permeability [30-32]. It has been reported that its activity decreases the breakdown of the glycocalyx and improves renal perfusion, thereby reducing renal dysfunction [33,34]. Doxorubicin, on the other hand, is a versatile and effective anticancer used in several types of neoplasms. However, it triggers cardiotoxicity, hepatotoxicity, nephrotoxicity, pulmonary, and hematological toxicity $[35,36]$. After performing the multivariate and multilevel analysis, it was found that the therapeutic set is inversely associated with a reduction in GFR, that is, its use is less harmful to the kidneys, causing mild protection. This fact can occur due to the beneficial action of dexamethasone in 
protecting and recovering from kidney damage. There is still a deficit of scientific findings specifically about this protocol. However, when drugs are analyzed separately, there is a greater collection.

The VCD protocol was statistically relevant in the analyses, being independently related to the decrease in GFR, causing an impact more than ten times. The proteasome inhibitor antineoplastic, such as Vecalde present in the VCD protocol, is widely used for the treatment of MM and mantle cell lymphoma. Its action consists of the degradation of proteins, essential for cell hemostasis, and the accumulation of these fragments triggers the process of cell death [37]. In addition, it also has the effect of minimizing the action of the immune system $[38,39]$. There are reports of its benefits in the kidney, causing an improvement in renal function. Another study points out that there is a need for further analysis about the dosage of the drug to verify its efficiency [40]. The second member of the scheme is dexamethasone, whose beneficial action on the renal system reduces the possibilities of dysfunction and progression to the installation of CKD [35]. Cyclophosphamide is the last component of the VCD protocol, being conceptualized as an immunosuppressive and antineoplastic drug that has ample potential for nephrotoxicity. This research showed a direct association between renal dysfunction and the use of this protocol (VCD), which, despite comprising a drug considered nephroprotective, has more dominant characteristics of the action of the two drugs that are harmful to the kidneys. The properties of Vecalde support the findings in which most patients are in the first and second chemotherapy cycles.

The use of bisphosphonates stands out as harmful to the kidneys with a decrease in GFR, and this risk can vary between 3 to almost 4 times. Bisphosphonates, zoledronate, and pamidronate are used to restore bone mineral density, minimizing the possibility of fractures and treating malignant hypercalcemia [41]. In the context of cancers, bisphosphonates hinder malignant osteolysis, neoplastic growth, and bone destruction, and, in particular, zoledronate has antitumor and antiangiogenic characteristics [42]. This pharmacological group can be used in patients with $\mathrm{MM}$ and bone metastases due to breast, prostate, lung, and other soft tissue cancer [43]. It should be noted that nitrogenous bisphosphonates do not have specific enzymes that recognize and metabolize them, causing an accumulation of bisphosphonates in the cortex and renal medulla [44]. When the drug cannot be absorbed, it is excreted unchanged by the kidney, damaging it, a fact that can be modified according to the dose administered [45]. About $63 \%$ of patients with MM developed renal dysfunction due to the use of this drug [46]. The literature largely reinforces the present research above, confirming the harmful action of bisphosphonates in the kidneys. Its use must be accompanied by more rigorous monitoring of renal function at each cycle and/or application with verification of serum creatinine, urea, electrolyte values, in addition to the calculation of GFR.

In oncohematological patients, the prevalence of renal disorders is high, affecting women more, increasing the probability of the event by more than two times, and the diagnosis of MM has an independent influence, increasing the chance of episodes with reduced GFR by 5.75 times. The pharmacological protocol CalgB is inversely associated with GFR reduction events, minimizing the chances of renal dysfunction by 0.23 times. On the other hand, the VDC, zoledronate and pamidronate 
therapeutic regimens are related to higher chances of episodes of reduced GFR, and specifically, the VDC protocol increases the chances of occurring this change by more than ten times.

\section{Declarations}

Funding: N/A

Conflicts of interest/Competing interests: N/A

Availability of data and material: N/A

Code availability: N/A

Authors' contribution: Priscila Nunes Costa Travassos, Paulo Goberlânio de Barros Silva and Milena Oliveira Freitas performed the data survey and performed the statistical analyzes. They read and approved the final version.

Marcus Davis Machado Braga, Fernando Barroso Duarte and Jéssica Karen de Oliveira Maia, were responsible for revising the text and writing the article. They read and approved the final version.

Helena Pitombeira and Jacqueline Holanda de Sousa designed the model, conducted the research, revised the text and read and approved the final version.

Ana Paula Negreiros Nunes Alves designed the study. She read and approved the final version.

Ethics approval: The research is in accordance with ethical principles, and the Ethics Committee for Research on Human Beings of the Faculty of Medicine (UFC) was firstly approved with CAAE 87952818.7.0000.5054 and then by the Ethics Committee of the Walter Cantídeo University Hospital (UFC) under CAAE number 87952818.7.3001.5045

Consent to participate: N/A

Consent for publication: The authors are aware of the possible publication and everyone agrees with it.

\section{References}

1. Inca (2012). ABC do câncer: abordagens básicas para o controle do câncer. Rev e Atual 1-134.

2. Devita JR VT, Lawrence TL, Rosenberg SA (2011). DeVita, Hellman and Rosenberg's cancer: principles and practice of oncology. Philadelphia: Lippincott Williams \& Wilkins 9:1-384.

3. Cohen EP, Krzesinski JM, Launay-Vacher V (2015). Onco-Nephrology: Core Curriculum 2015. Am J Kidney Dis 66:869-883.

4. Arellano J, Hernandez RK, Wade SW (2015). Prevalence of renal impairment and use of nephrotoxic agents among patients with bone metastases from solid tumors in the United States. Cancer Med 
4:713-720.

5. Lahoti A, Kantarjian H, Slahudeen AK et al (2010). Predictors and outcome of acute kidney injury in patients with acute myelogenous leukemia or high-risk myelodysplastic syndrome. Cancer 116:4063-4068.

6. Dimopoulos MA, Terpos E, Chanan-Khan A et al (2010). Renal impairment in patients with multiple myeloma: a consensus statement on behalf of the International Myeloma Working Group. J Clin Oncol 28:4976-4984.

7. Christiansen CF, Johansen MB, Langeberg WL et al (2011). Incidence of acute kidney injury in cancer patients: a Danish population-based cohort study. Eur J Intern Med 22:399-406.

8. Heher EC, Rennke HG, Laubach JP et al (2013). Kidney disease and multiple myeloma. Clin J Am Soc Nephrol 8:2007-2017.

9. Zeng X, McMahon GM, Brunelli SM et al (2014). Incidence, outcomes, and comparisons across definitions of AKI in hospitalized individuals. Clin J Am Soc Nephrol 9:12-20.

10. . Garcia MR, Ariza LC, Hito PD (2013). Actualización en técnicas continuas de reemplazo renal. Enferm Intensiva 24:113-119.

11. Lameire N, Van BW, Vanholder R (2008). Acute renal problems in the critically ill cancer patient. Curr Opin Crit Care 14:635-646.

12. Chuva T, Maximino J, Barbosa J et al (2016). Haematological malignancies and acute kidney injury requiring nephrology consultation: challenging the worst of the worst. Clin Kidney J 9:418-423.

13. . Palevsky PM, Liu KD, Brophy PD et al (2013). KDOQI US commentary on the 2012 KDIGO clinical practice guideline for acute kidney injury. Am J Kidney Dis 61:1-141.

14. Rodrigues L, Neves M, Sá H et al (2014). Severe acute kidney injury and multiple myeloma: Evaluation of kidney and patient prognostic factors. Eur J Intern Med 25:652-656.

15. . Perazella MA, Moeckel GW (2010). Nephrotoxicity from chemotherapeutic agents: clinical manifestations, pathobiology, and prevention/therapy. Semin Nephrol 30:570-581.

16. Perazella MA (2012). Onco-nephrology: renal toxicities of chemotherapeutic agents. Clin J Am Soc Nephrol 7:1713-1721.

17. Strati P Chaffe KG, Achenbach SJ et al (2017). Renal insufficiency is an independent prognostic factor in patients with chronic lymphocytic leucemia. Haematologica 102:e22-e25.

18. Silva ROP, Brandão KMA, Pinto PVM et al (2009). Multiple myeloma: clinical and laboratory characteristics in the diagnosis and prognostic study. Rev Bras Hematol Hemoter 31:63-8.

19. Sakae TM, Santos NAF, Baldessar MZ (2012). Sobrevida de pacientes portadores de mieloma múltiplo atendidos em hospital de referência no Sul de Santa Catarina. Rev Bras Clin Med 8:216-21.

20. Furini AAC, Alves MC, Madeira EB et al (2018). Perfil de pacientes com diagnóstico patológico de mieloma múltiplo em hospital de ensino. Arq Ciênc Saúde 25:61-64.

21. Maiolino A, Magalhães RJP (2007). Mieloma múltiplo e insuficiência renal. Rev Bras Hematol e Hemot 29:86-91. 
22. Quian Y, Bhowmik D, Bond C et al (2017). Renal impairment and use of nephrotoxic agents in patients with multiple myeloma in the clinical practice setting in the United States. Cancer Med 6:1523-1530.

23. Rodrigues JSM, Ferreira NMLA (2010). Caracterização do perfil epidemiológico do câncer em uma cidade do interior paulista: conhecer para intervir. Rev Bras Cancerol 56:431-41.

24. Hutchison CA, Cockwell P, Stringer S et al (2011). Early reduction of serum-free light chains associates with renal recovery in myeloma kidney. J Am Soc Nephrol 22:1129-1136.

25. Tillmann FP (2015). Daily postdilutional hemodiafiltration with FX800 polysulfone dialyzers for removing kappa light chains in multiple myeloma-induced kidney injury. Indian J Nephrol 25:237341.

26. Rabrenovic V, Mijušković Z, Marjanović S et al (2015). Kidney failure as an unusual initial presentation of biclonal gammopathy $\operatorname{lgD}$ multiple myelomaassociated with light chain disease. -a case report. Vojnosanit Pregl 72:196-199.

27. Ecotiérel L, Thierry A, Debiais-Delpech C et al (2016). Prognostic value of kidney biopsy in myeloma cast nephropathy: a retrospective study of 70 patients. Nephrol Dial Transplant 31:64-72.

28. Jain P, Gulati S, Seth R et al (2014). Vincristine-induced neuropathy in childhood all (acute lymphoblastic leukemia) survivors: prevalence and electrophysiological characteristics. J Child Neurol 29:932-937.

29. Purser MJ, Johnston DL (2014). Chemotherapy-induced peripheral neuropathy among paediatric oncology patients. Can J Neurol Sci 41:442-447.

30. Leeuw K, Niemeijer AS, Eshuis J et al (2016). Effect and mechanism of hydrocortisone on organ function in patients with severe burns. J Crit Care 36:200-206.

31. Rhodes A, Evans LE, Alhazzani W et al (2017). Surviving sepsis campaign: international guidelines for management of sepsis and septic shock: 2016. Crit Care Med 45:486-552.

32. Barabutis N, Barabutis N, Khangoora V et al (2017). Hydrocortisone and ascorbic acid synergistically prevent and repair lipopolysaccharide-induced pulmonary endothelial barrier dysfunction. Chest 152:954-962.

33. Zhang J, Yao Y, Ciao F et al (2013). Administration of dexamethasone protects mice against ischemia/reperfusion induced renal injury by suppressing PI3K/AKT signaling. Int J Clin Exp Pathol 6:2366-2375.

34. Yu W, Zhang S, Fu S et al (2019). Dexamethasone protects the glycocalyx on the kidney microvascular endothelium during severe acute pancreatitis. J Zhejiang Univ-Sci B (Biomed \& Biotechnol) 20:355-362.

35. Zhang Z, Yu X, Wang Z et al (2015). Anthracyclines potentiate anti-tumor immunity: A new opportunity for chemoimmunotherapy. Cancer Lett 369:331-335.

36. Ben P, Ben P, Zhang Z et al (2016). LuoL-Theanine attenuates cadmium-induced neurotoxicity through the inhibition of oxidative damage and tau hyperphosphorylation. Neurotoxicology 57:95103. 
37. Mujtaba T, Dou QP (2011). Advances in the understanding of mechanisms and therapeutic use of bortezomib. Discov Med 12:471-480.

38. Mohty M, Brissot E, Savani BN (2013). Effects of bortezomib on the immune system: a focus on immune regulation. Biol Blood Marrow Transplant 19:1416-1420.

39. Zafar MSH, Khan AA, Aggarwal S et al (2018). Efficacy and tolerability of bortezomib and dexamethasone in newly diagnosed multiple myeloma. South Asian J Cancer 7:58-60.

40. Chanan-khan AA, Kaufman JL, Mehta J et al (2007). Activity and safety of bortezomib in multiple myeloma patients with advanced renal failure: a multicenter retrospective study. Blood 109:26042606.

41. Black DM, Reide IR, Cauley JA et al (2015). The effect of 6 versus 9 years of zoledronic acid treatment in osteoporosis: a randomized second extension to the HORIZON-Pivotal Fracture Trial (PFT). J Bone Miner Res 30:934-944.

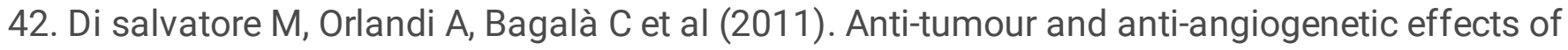
zoledronic acid on human non-small-cell lung cancer cell line. Cell Prolif 44:139-146.

43. Arany I, Clark JS, Ember et al (2011). Epigenetic modifiers exert renal toxicity through induction of p66shc. Anticancer Res 31:3267-3271.

44. Arany I, Hall S, Faisal et al (2017). Nicotine Exposure Augments Renal Toxicity of 5-aza-cytidine Through p66shc: Prevention by Resveratrol. Anticancer Res 37:4075-4079.

45. Sanchez MPR, Pereira R, Nogeuir LM et al (2016). Dental implants in patients with bone metabolic diseases under bisphosphonate therapy a literature review. INPerio 1:84-94.

46. Weiss HM, Pfaar U, Schweitzer A et al (2008). Biodistribution and plasma protein binding of zoledronic acid. Drug Metab Dispos 36:2043-2049. 